\title{
Nitric Oxide-Directed Synaptic Remodeling in the Adult Mammal CNS
}

\author{
Carmen R. Sunico, Federico Portillo, David González-Forero, and Bernardo Moreno-López \\ Área de Fisiología, Facultad de Medicina, Universidad de Cádiz, 11003 Cádiz, Spain
}

In adult mammals, learning, memory, and restoration of sensorimotor lost functions imply synaptic reorganization that requires diffusible messengers-mediated communication between presynaptic and postsynaptic structures. A candidate molecule to accomplish this function is the gaseous intercellular messenger nitric oxide (NO), which is involved in synaptogenesis and projection refinement during development; however, the role of NO in synaptic reorganization processes in adulthood remains to be established. In this work, we tested the hypothesis that this free radical is a mediator in the adult mammal CNS synaptic remodeling processes using a model of hypoglossal axonal injury recently developed by us. Axonal injury-induced disconnection of motoneurons from myocytes produces withdrawal of synaptic inputs to motoneurons and concomitant upregulation of the neuronal isoform of NO synthase (NOS-I). After recovery of the neuromuscular function, synaptic coverage is reestablished and NOS-I is downregulated. We also report, by using functional and morphological approaches, that chronic inhibition of the NO/cGMP pathway prevents synaptic withdrawal evoked by axon injury, despite the persistent muscle disconnection. After successful withdrawal of synaptic boutons, inhibition of NO synthesis, but not of cGMP, accelerated the recovery of synaptic coverage, although neuromuscular disconnection was maintained. Furthermore, protein $S$-nitrosylation was upregulated after nerve injury, and this effect was reversed by NOS-I inhibition. Our results suggest that during synaptic remodeling in the adult CNS, NO acts as a signal for synaptic detachment and inhibits synapse formation by cGMP-dependent and probably $S$-nitrosylation-mediated mechanisms, respectively. We also suggest a feasible role of NO in neurological disorders coursing with NOS-I upregulation.

Key words: synaptic plasticity; nitric oxide; cGMP; hypoglossal motoneurons; degenerative processes; regenerative processes

\section{Introduction}

Synaptogenic phenomena, the dynamic processes that include the modification and elimination of existing synapses and the generation of new synapses (Benson et al., 2001), are the substratum for synaptic reorganization occurring in learning, memory formation, and restoration of lost sensorimotor functions. Knowledge of the molecular machinery that gives the instructions "come" or "go away" to synaptic boutons and underlies the establishment and maintenance of synapses during synaptic remodeling in such circumstances has basic and clinical relevancy. An increasing number of endogenous molecules that underpin the formation and refinement of synapses during early development or in in vitro models are being identified (Benson et al., 2001; Garner et al., 2002; Yamagata et al., 2003); however, scarce information is available about the molecular basis underlying synaptic rearrangement in adulthood.

It is well known that disruption of the trophic communication

Received Aug. 3, 2004; revised Dec. 20, 2004; accepted Dec. 21, 2004

This work was supported by a grant from the Ministerio de Ciencia y Tecnología, Spain (BFI2001-3186). D.G.-F. was supported by a grant from the Junta de Andalucía, Spain (PAI/COORD-GR/PR/2001-052). We thank Dr. C. Estrada for critical reading of this manuscript, Dr. J. Rodrigo for kindly providing the NOS-II antibody, and Antonio Torres for his skillful technical assistance.

Correspondence should be addressed to Dr. Bernardo Moreno-López, Área de Fisiología, Facultad de Medicina, Universidad de Cádiz, Plaza Falla, 9, 11003 Cádiz, Spain. E-mail: bernardo.moreno@uca.es.

DOI:10.1523/JNEUROSCI.4600-04.2005

Copyright $\odot 2005$ Society for Neuroscience $\quad$ 0270-6474/05/251448-11\$15.00/0 between motoneurons and their target myocytes by nerve injury induces reductions in the motoneuron response to the incoming afferent activity, together with a marked reduction in the number and strength of synaptic inputs (Mendell, 1984; Titmus and Faber, 1990; González-Forero et al., 2004a,b). These alterations are usually transient: the firing properties and the synaptic density recover with muscle reinnervation (González-Forero et al., 2004a,b). Therefore, we believe that our recently developed model of hypoglossal axonal injury (González-Forero et al., 2004b) can appropriately be used to determine the molecular mechanisms underlying withdrawal, formation, and stabilization of synapses in the adult CNS.

Diffusible molecules forming links between presynaptic and postsynaptic structures are probably synthesized in the neuron with axonal damage to signal the detachment of its afferent synaptic terminals and prevent the formation of new synapses until trophic communication is reestablished with an appropriate target. Several properties make nitric oxide (NO) a suitable candidate for the role of mediator in synaptic remodeling processes: (1) NO is a gaseous free radical molecule that can freely cross cell membranes, thus acting as a three-dimensional messenger; (2) neuronal NO modulates synaptic activity by regulating neurotransmitter release, an effect that requires activation of soluble guanylyl cyclase (sGC) in the target synapses (Prast and Philippu, 2001); (3) NO participates in synaptic plastic phenomena such as long-term potentiation and depression (Holscher, 1997) as well 
as in synaptogenesis and projection refinement during development (Roskams et al., 1994; Wu et al., 1994); and (4) a broad spectrum of insults to nerves induces upregulation of the neuronal isoform of NO synthase (NOS-I) in motoneurons, which normally lack this enzyme, followed by downregulation some weeks after the nerve lesion (Yu, 1997). No information exists, however, about the relationship between NOS-I expression and the main central events induced by nerve lesion.

Here we provide evidence suggesting that during synaptic remodeling in the adult CNS, induced neuronal NO synthesis is a signal for synaptic detachment and inhibits synapse formation by cGMP-dependent and probably $S$-nitrosylation-mediated mechanisms, respectively. We then suggest a role for $\mathrm{NO}$ as an antisynaptotrophic and anti-synaptogenic factor in adulthood. We also discuss a feasible role for NO underlying diverse nervous afflictions.

\section{Materials and Methods}

Adult male Wistar rats $(250-400 \mathrm{~g})$ were used throughout this study. Animals were cared for and handled in accordance with the guidelines of the European Union Council (86/609/UE) and the Spanish regulations (BOE 67/8509-12) on the use of laboratory animals. Animals were anesthetized with chloral hydrate $(0.5 \mathrm{~g} / \mathrm{kg}$, i.p. $)$, and the right hypoglossal (XIIth) nerve was thoroughly crushed just proximal to nerve bifurcation, as described previously (González-Forero et al., 2004b), using microdissecting tweezers applied for $30 \mathrm{~s}$. Animals were allowed to survive 1, 3, 7, 15,22 , or $30 \mathrm{~d}$ after the crushing. This surgery was not performed in the control group, and in sham-operated animals the nerve was dissected but crushing was omitted.

Histological procedures. Animals were anesthetized with ketamine (35 $\mathrm{mg} / \mathrm{kg}$, i.m.) and xylidine-dihydrothiazine ( $1 \mathrm{mg} / \mathrm{kg}$, i.m.), injected intraventricularly with heparin, and perfused transcardially first with PBS, followed by $4 \%$ paraformaldehyde in $0.1 \mathrm{~m}$ phosphate buffer (PB), $\mathrm{pH}$ 7.4 , at $4^{\circ} \mathrm{C}$. The brains were removed, postfixed for $2 \mathrm{~h}$ in the same fixative solution, and cryoprotected by overnight immersion in 30\% sucrose in $\mathrm{PB}$ at $4^{\circ} \mathrm{C}$. Serial coronal sections (10 or $30 \mu \mathrm{m}$ thick) from brainstem were obtained using a cryostat and stored at $-20^{\circ} \mathrm{C}$ in a cryoprotectant solution (glycerol and PBS, pH 7.4, 1:1 in volume).

Nitrergic neurons were identified by either reduced NADPH diaphorase (NADPH-d) histochemistry or NOS-I immunohistochemistry in $30-\mu \mathrm{m}$-thick sections. NADPH-d activity was made visible by incubation of the tissue in a mixture containing $1 \mathrm{~mm} \beta-\mathrm{NADPH}, 1 \mathrm{~mm}$ nitroblue tetrazolium, and $0.1 \%$ Triton X-100 in $0.1 \mathrm{M}$ Tris buffer, $\mathrm{pH} 8.0$, for $30 \mathrm{~min}$ at $37^{\circ} \mathrm{C}$. After extensive washing, the tissue was dehydrated, mounted with DePeX, and analyzed under light microscopy. For NOS-I immunohistochemistry, free-floating sections were rinsed in PBS and immersed in $2.5 \%(\mathrm{w} / \mathrm{v})$ bovine serum albumin, $0.25 \%(\mathrm{w} / \mathrm{v})$ sodium azide, and $0.1 \%(\mathrm{v} / \mathrm{v})$ Triton X-100 in PBS for $30 \mathrm{~min}$, followed by incubation for $2 \mathrm{~d}$ at $4^{\circ} \mathrm{C}$ with an antibody raised in rabbit against the human NOS-I (1:16,000; Chemicon, Temecula, CA). Subsequently, the tissue was rinsed in PBS and incubated for $2 \mathrm{~h}$ at room temperature with an anti-rabbit IgG labeled with cyanine 5 (Cy5) (1:200; Jackson ImmunoResearch, West Grove, PA). After sections were washed with PBS, they were mounted on slides with a solution containing propyl gallate $(0.1 \mathrm{~mm}$ in $\mathrm{PBS} /$ glycerol 1:9). To investigate the expression of the inducible isoform of NOS (NOS-II) in the hypoglossal nuclei (HNs) in response to XIIth nerve injury, we used an antibody raised in rabbit against NOS-II (1: 20,000; a gift from Dr. J. Rodrigo, Consejo Superior de Investigaciones Científicas, Madrid, Spain).

In another group of anesthetized animals (as above), $50 \mu \mathrm{l}$ of a solution containing $1 \%$ of the retrograde tracer aminostilbamidine methanesulfonate (FluoroGold; Molecular Probes, Eugene, OR) in PBS was injected into the tip of the tongue to identify hypoglossal motoneurons (HMNs). Seven days after the tracer injection, animals were perfused (control group) or subjected to nerve lesion (experimental group) and killed 7 or $15 \mathrm{~d}$ after XIIth nerve crushing. Immunohistochemical detection of the synaptic marker synaptophysin was performed by incubation with a specific anti-synaptophysin rabbit polyclonal antibody (1:200; Zymed Laboratories, San Francisco, CA; overnight, room temperature) on sections ( $10 \mu \mathrm{m}$ thick) adhered to gelatin-coated slides. Subsequently, the tissue was rinsed with PBS and incubated for $2 \mathrm{~h}$ at room temperature with an anti-rabbit IgG labeled with $\mathrm{Cy} 5$ as secondary antibody. Alternatively, to investigate protein $S$-nitrosylation as a possible mechanism of action of NO in the HN after XIIth nerve injury, sections were incubated with a specific anti-S-nitrosylated cysteine rabbit polyclonal antibody (1:400; Alpha Diagnostic, San Antonio, TX; overnight, $4^{\circ} \mathrm{C}$ ). Omission of primary antibodies resulted in no detectable staining in all cases.

Slides were analyzed using an Olympus (Tokyo, Japan) BX60 epifluorescence microscope for NADPH-d or a Leica (Nussloch, Germany) confocal microscope for fluorescence. For low-magnification analysis, images including both HNs were captured and processed for background subtraction to obtain the maximum dynamic range of intensities (from 0 to 250) and analyzed using the software provided by Leica. In all cases, the area delimiting the $\mathrm{HN}$ was traced manually, and for each image, the histogram of fluorescence intensities (see Fig. $4 A, C$ ) and mean fluorescence intensity (see Figs. $4 A, C, 5 A, 7 A, 8 G$ ) (i.e., the average of pixel intensity in the outlined area) of synaptophysin or $S$-nitrosylated-cysteine immunofluorescence were obtained in both the control and experimental hypoglossal regions. Data were collected from five to eight sections per animal in at least two animals in each condition. The number of synaptophysin-immunoreactive boutons bordering the soma of identified HMNs was quantified at high magnification and expressed relative to $100 \mu \mathrm{m}$ of membrane perimeter. All motoneurons were analyzed in a $z$-plane containing the nucleolus. One-way ANOVA and post hoc comparison tests at a level of significance of $p<0.05$ were used for the comparison of the different experimental conditions.

Physiological procedures. Rats were prepared for electromyographic and electroneurographic or unitary extracellular recordings as described previously (González-Forero et al., 2004b) (see Fig. 1 A). Briefly, under general anesthesia (chloral hydrate; as above), the animals were implanted bilaterally with Teflon-isolated silver bipolar electrodes fixed around the XIIth nerves. The compound muscle action potential (CMAP), evoked by XIIth nerve stimulation $(50 \mu \mathrm{s}, 1 \mathrm{~Hz},<0.1 \mathrm{~mA})$, was recorded by means of two stainless steel Teflon-coated hook electrodes implanted in the genioglossus muscle (see Fig. $1 \mathrm{~A}$ ). Electroneurographic activity was recorded using the same electrodes implanted on the XIIth nerves for stimulation purposes. The signals were visualized, transferred, and stored in a computer. Data from electroneurographic recordings have been reported previously (González-Forero et al., 2004b) and have been used here to study the relationship between the number of nitrergic neurons and the level of activity in the XIIth nerve (see Fig. 1).

Rats used for extracellular unitary recordings of HMNs, anesthetized as indicated previously, were injected intramuscularly with atropine sulfate $(0.2 \mathrm{mg} / \mathrm{kg})$ and dexamethasone sodium phosphate $(0.8 \mathrm{mg} / \mathrm{kg})$. A ventral approach was used to cannulate trachea, bladder, and femoral artery and vein. Bipolar stimulating electrodes were implanted bilaterally on XIIth nerves. Subsequently, animals were vagotomized, decerebrated, paralyzed with gallamine triethiodide $(20 \mathrm{mg} / \mathrm{kg}$, i.v., initially; $4 \mathrm{mg} / \mathrm{kg}$, i.v., as needed), and mechanically ventilated. Expired $\mathrm{CO}_{2}$ and $\mathrm{O}_{2}$ were monitored continuously (Eliza duo; Gambro Engström, Bromma, Sweden); data were stored in a computer. The end-tidal $\mathrm{CO}_{2}\left(\mathrm{ET}_{\mathrm{CO}_{2}}\right)$ was changed ( $\sim 3$ to $\sim 7.5 \%$ ) as required by adjusting ventilation parameters (tidal volume and/or respiratory rate). Expired $\mathrm{O}_{2}(14-19 \%)$ was always higher than values below which hypoxia-induced alterations have been reported (Hwang et al., 1983). Femoral arterial blood pressure (95 \pm 15 $\mathrm{mmHg}$ ) and rectal temperature $\left(37 \pm 1^{\circ} \mathrm{C}\right)$ were steadily maintained. When necessary, a modified Ringer's solution $\left(2 \mathrm{ml}\right.$ of $1 \mathrm{M} \mathrm{NaHCO}_{3}$ and $10 \mathrm{ml}$ of $5 \%$ glucose in $38 \mathrm{ml}$ of Ringer's solution) was infused through the femoral vein. Before the beginning of neuronal recording, animals were allowed to stabilize for $30 \mathrm{~min}$ after decerebration; $\mathrm{ET}_{\mathrm{CO}_{2}}$ was maintained at $4.8-5.2 \%$. After that, a glass micropipette (1-3 M $\Omega$ ) was visually guided and advanced through the brainstem to the HN. The correct position of the micropipette was confirmed by recording the characteristic inspiratory pattern of the $\mathrm{HN}$ and the presence of the antidromic field potential elicited by electrical stimulation of the ipsilateral XIIth nerve (see Fig. $1 A$, inset, asterisk). HMNs were positively identified by 
their antidromic activation from the XIIth nerve and by the collision test (see Fig. $1 A$, inset). The electrical signals were amplified and filtered at a bandwidth of $10 \mathrm{~Hz}-10 \mathrm{kHz}$ for display and digitalization purposes. Responses of HMNs were recorded in response to a change in $\mathrm{ET}_{\mathrm{CO}_{2}}$ from hypocapnic ( 3\%) to hypercapnic $(\sim 7.5 \%)$ conditions. Only inspiratory HMNs discharging at basal conditions $\left(\mathrm{ET}_{\mathrm{CO}_{2}}=4.8-5.2 \%\right)$ were considered in this study.

Electromyographic, electroneurographic, and unitary discharge signals, percentages of expired $\mathrm{CO}_{2}$ and $\mathrm{O}_{2}$, and arterial pressure recordings were amplified, filtered, transferred, and stored in a computer for off-line analysis. To assess the number of functional motor units, the area of CMAP evoked by XIIth nerve stimulation was measured in control and experimental animals. Comparison between experimental and control values at different times after injury was performed using the nonparametric MannWhitney $U$ test. The area of integrated $(\tau=20 \mathrm{~ms})$ burst activity in electroneurographic recordings was measured automatically.

Unitary HMN activity was recorded and stored together with arterial femoral pressure and expired $\mathrm{CO}_{2}$ and $\mathrm{O}_{2}$ percentages. The mean firing rate ( $\mathrm{mFR}$ ) (in spikes per second) relative to burst events and the cycle duration (see Fig. $1 C$ ) to calculate burst rate (BR) (in bursts per minute) were measured in each motoneuron over the range of $\mathrm{ET}_{\mathrm{CO}_{2}}$ tested. These parameters were correlated with the variable $\mathrm{ET}_{\mathrm{CO}_{2}}$ (expressed as a percentage) using linear regression analysis. It was thus possible to obtain two equations characterizing the behavior of an $\mathrm{HMN}$ in response to changes in $\mathrm{ET}_{\mathrm{CO}_{2}}: \mathrm{mFR}=$ $S_{\mathrm{mFR}} \times \mathrm{ET}_{\mathrm{CO}_{2}}+I_{\mathrm{mFR}}$ and $\mathrm{BR}=S_{\mathrm{BR}} \times$ $\mathrm{ET}_{\mathrm{CO}_{2}}+I_{\mathrm{BR}}$, where $S$ was the slope, i.e., the neuronal gain or sensitivity for each parameter with respect to $\mathrm{ET}_{\mathrm{CO}_{2}}$ variation. One-way ANOVA and post hoc comparison tests at a level of significance of $p<0.05$ were used for the comparison of the mean parameters relative to different experimental conditions.

Administration of NOS and $s G C$ inhibitors. Administration of chemicals began on the day of crushing or on day 7 after lesion to study the role of the NO/cGMP pathway in central degenerative or regenerative processes, respectively. Rats were injected intraperitoneally with the broad-spectrum NOS inhibitor $\mathrm{N}^{\omega}$-nitro-L-arginine methyl ester (L-NAME) $\left(90 \mathrm{mg} \cdot \mathrm{kg}^{-1} \cdot \mathrm{d}^{-1}\right)$, the inactive stereoisomer D-NAME $\left(90 \mathrm{mg} \cdot \mathrm{kg}^{-1} \cdot \mathrm{d}^{-1}\right)$, the relatively specific NOS-I inhibitor 7-nitroindazole (7-NI) $\left(30 \mathrm{mg} \cdot \mathrm{kg}^{-1} \cdot \mathrm{d}^{-1}\right)$, the specific NOS-II inhibitor aminoguanidine (AG) $\left(100 \mathrm{mg} \cdot \mathrm{kg}^{-1} \cdot \mathrm{d}^{-1}\right)$, or the specific sGC inhibitor ${ }^{1} \mathrm{H}$-[1,2,4] oxadiazolo[4,3-a] quinoxalin-1-one (ODQ) (2 $\left.\mathrm{mg} \cdot \mathrm{kg}^{-1} \cdot \mathrm{d}^{-1}\right)$. Another group of animals received the vehicle solution for $7-\mathrm{NI}$ and ODQ (1\% dimethylsulfoxide in PBS). In our hands, the injected dose of L-NAME produced a transient increase in the arterial blood pressure that returned to control values $6 \mathrm{~h}$ after injection, and it was not altered by the NOS-I inhibitor 7-NI. The amounts of NOS-I and endothelial isoform of NOS (NOS-III) remained as in control animals after chronic treatment with L-NAME (Moreno-López et al., 2004). Either perfusion or recording sessions were performed at least $18 \mathrm{~h}$ after the last injection of chemicals.

The drugs were systemically administered for several reasons. First, intracerebral or intranuclear drug administration could cause a surgical trauma that might upregulate NOS-I and initiate the expression of
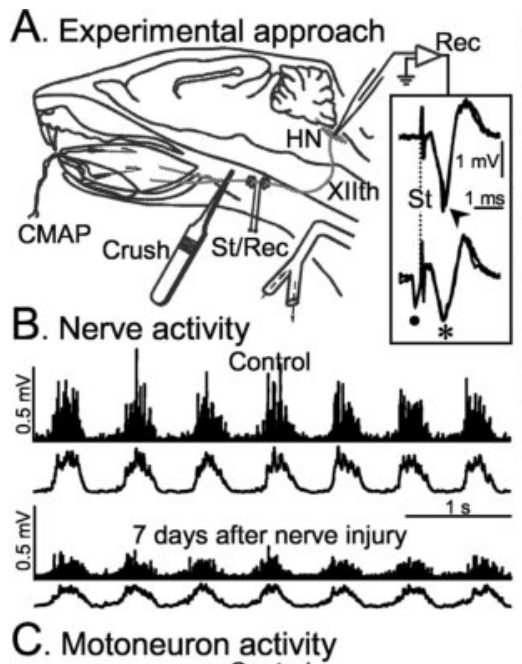
activity were recorded in anesthetized animals by means of electrodes implanted in the genioglossus muscle and in the XIIth nerve ing arterial pressure were obtained in decerebrated, vagotomized, and paralyzed rats. Inset, HMNs were identified by their antidromic activation from the electrode (St/Rec) implanted in the XIlth nerve and by the collision test between spontaneous ) and antidromic (arrowhead) evoked action potentials. When the stimulus was triggered by a spontaneous spike graphic recordings of the XIlth nerve (top traces) and their integrated signal (bottom traces) in the control condition and $7 \mathrm{~d}$ after of $\mathrm{HMNs}$ recorded at basal conditions $\left(\mathrm{ET}_{\mathrm{CO}_{2}}=4.8-5.2 \%\right)$ in the control stage and on day 7 after ipsilateral XIIth nerve crushing. $C D$, Cycle duration. D-G, Photomicrographs obtained from coronal sections at different rostrocaudal levels processed by NADPHsides are illustrated in each panel. $D$, Insets show details of the boxed areas showing NADPH-positive neurons. Dashed lines 列 列 lesioned) and left (or unoperated) sides, measured on the integrated XIlth nerve activity, and the $\mathrm{mFR}(\mathrm{O})$ obtained from the pool, after XIIth nerve crushing, relative to the control group (C). Mean values for three animals or $>20 \mathrm{HMNs}$ are represented fo control) after XIIth nerve lesion. Values are means \pm SEM for three animals. Insets, CMAPs evoked by single shock stimulation (arrowheads) of the XIlth nerve at the indicated conditions. Scale bars: $D-G, I, 500 \mu \mathrm{m} ; D$, insets, $50 \mu \mathrm{m}$.

NOS-II in the proximity of the lesioned area (Rao et al., 1999; Petrov et al., 2000; our observations), thereby creating a nonphysiological source of NO production. Furthermore, because the nucleus of the solitary tract, very close and functionally related to the $\mathrm{HN}$, contains nitrergic neurons (Rodrigo et al., 1994), a local perfusion would not guarantee an action exclusively on motoneurons. To test the effect of systemic NOS inhibition on the morphofunctional characteristics of HMNs, we studied the firing properties and synaptic coverage of motoneurons (see Figs. $3 E, F, 5 A, B$ ) in a group of noninjured rats treated with L-NAME $\left(90 \mathrm{mg} \cdot \mathrm{kg}^{-1} \cdot \mathrm{d}^{-1}\right)$ for $7 \mathrm{~d}$.

\section{Results}

Using a model of hypoglossal axonal injury that we developed recently (González-Forero et al., 2004b) (Fig. 1A), we tested the hypothesis that NO, a short-lived diffusible messenger, is a mediator in the adult mammal CNS synaptic remodeling processes. 
We demonstrated, using in vivo physiological preparations, that crushing of the XIIth nerve in adult rats reduces the inspiratoryrelated activities of nerves (Fig. $1 B, J$ ) and HMNs (Fig. 1C,J) 1 week after nerve lesion. These alterations were accompanied by a decrease in synaptic density in the $\mathrm{HN}$, as revealed by optical density analysis of the synaptic marker synaptophysin. The morphofunctional disturbances were reversed after muscle reinnervation (González-Forero et al., 2004b). Using morphological and physiological approaches, we investigated the effects of systemic and chronic administration of inhibitors of the NO/cGMP pathway in the central degenerative and regenerative processes occurring after nerve injury.

NOS expression is inversely related to motor nucleus activity NOS-I upregulation in axonally injured motoneurons is a well established fact $(\mathrm{Yu}, 1997)$. Consistent with this, we first studied the relationship between NOS expression and functional abnormalities induced by XIIth nerve crushing on the HMNs pool. The time course of NOS expression in the HN was determined by performing NADPH-d histochemistry in coronal slices from animals killed at different time points after nerve injury. In the control condition, some scattered nitrergic neurons were observed at various locations along the nucleus (Fig. $1 D, E$ ). The number of positive cell bodies increased at day 3 after lesion, reached a plateau between day 7 and day 15, and returned to control values 1 month after crushing (Fig. $1 F-H$ ). The performance of NOS-I immunohistochemistry $7 \mathrm{~d}$ after injury demonstrated that XIIth nerve crushing induced upregulation of the neuronal isoform of NOS in the HN (Fig. 1I), as reported previously (Yu, 1997). We also investigated the expression of the inducible isoform of NOS in the $\mathrm{HN}$ in response to nerve injury as a possible additional source of NO. No immunostaining was observed in the nucleus for NOS-II in sections obtained from animals in the control stage and 7 or $15 \mathrm{~d}$ after lesion. As a positive control, we immunostained activated macrophages in an experimentally induced inflammatory reaction (data not shown).

The time course of the basal XIIth nerve and HN activities (González-Forero et al., 2004b) after nerve lesion were similar to but the inverse of that obtained for NOS expression (Fig. $1 \mathrm{H}, \mathrm{J}$ ). The inspiratory electroneurographic activity recorded in the nerve proximal to the lesion, as well as the mean activity of the HMN pool in basal conditions, first declined and then recovered in a time-dependent manner after nerve crushing (Fig. $1 B, C, J$ ), in parallel with NOS upregulation and downregulation (Fig. $1 H$ ). To evaluate the degree of denervation and time course of muscle reinnervation after nerve injury, we recorded the CMAP evoked in the genioglossus muscle by electrical stimulation of the XIIth nerve (Fig. $1 A, K$ ). NOS downregulation and recovery of hypoglossal activity occurred in parallel to the reestablishment of neuromuscular functionality (Fig. $1 \mathrm{H}, \mathrm{J}, \mathrm{K}$ ). Inversely related linear regressions were confirmed statistically between the number of nitrergic neurons and the activity recorded in the nerve $(r=0.85$; $p<0.01)$ and in the nucleus $(r=0.93 ; p<0.01)$. Thus, there is a close spatiotemporal relationship between NOS-I expression and central functional alterations, supporting the hypothesis that NO synthesis could be involved in the central mechanisms underlying degenerative and regenerative processes after nerve injury.

\section{The NO/cGMP pathway mediates functional} degenerative processes

Most HMNs discharge bursts of action potentials that coincide with the inspiratory phase of breathing (Hwang et al., 1983) (Fig.
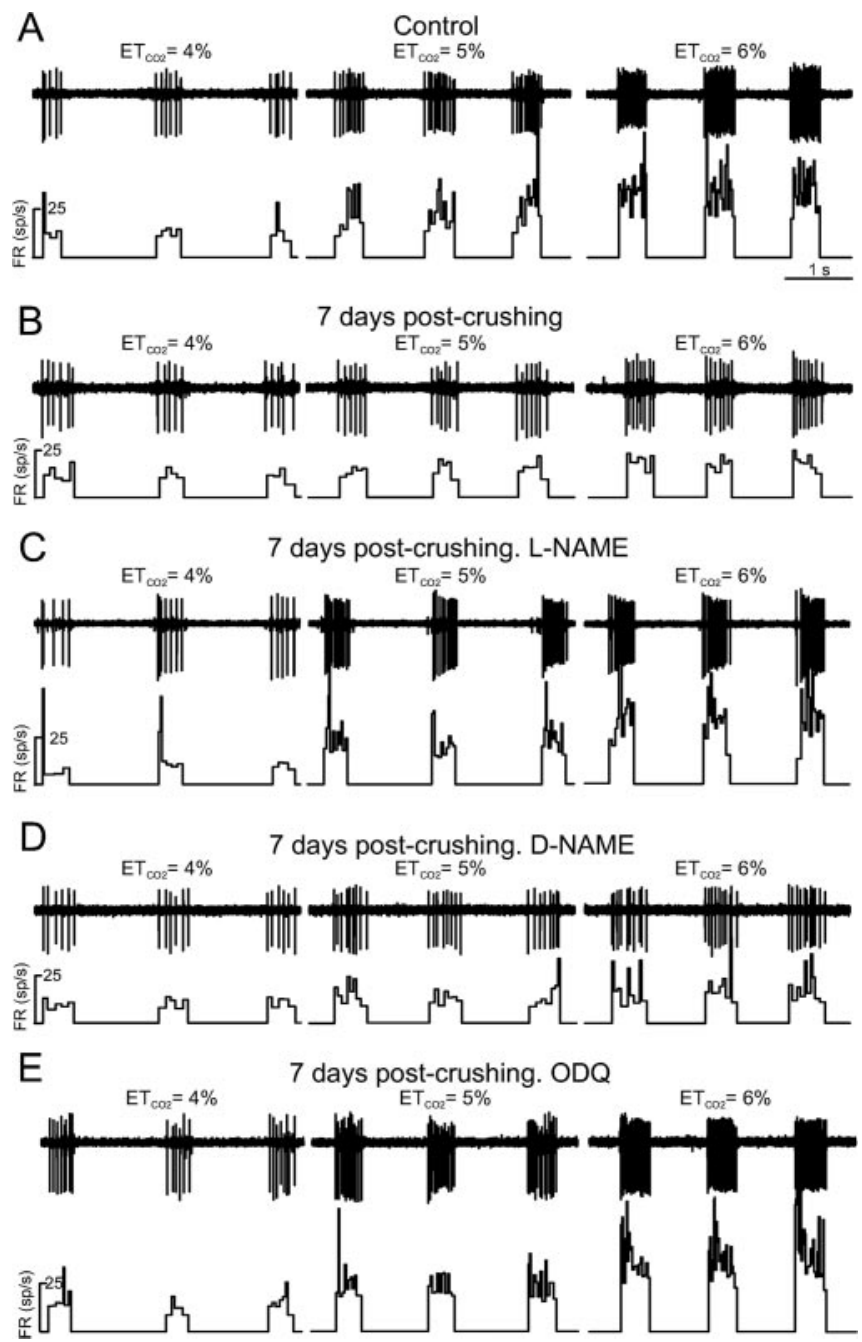

Figure 2. Involvement of the NO/CGMP pathway in central functional alterations. Discharge activity modulation at different $\mathrm{ET}_{\mathrm{CO}_{2}}$ levels for a control motoneuron $(A)$ and for motoneurons recorded $7 \mathrm{~d}$ after crushing without treatment $(B)$ or after chronic administration of the NOS inhibitor L-NAME $\left(90 \mathrm{mg} \cdot \mathrm{kg}^{-1} \cdot \mathrm{d}^{-1}\right.$, i.p.) (C), the inactive stereoisomer D-NAME $(90$ $\mathrm{mg} \cdot \mathrm{kg}^{-1} \cdot \mathrm{d}^{-1}$, i.p.) $(D)$, or the $\mathrm{sGC}$ inhibitor $\mathrm{ODQ}\left(2 \mathrm{mg} \cdot \mathrm{kg}^{-1} \cdot \mathrm{d}^{-1}\right.$, i.p.) (E) is shown. Chemical treatments began on crushing day. Traces represent the extracellular unitary activity (top traces) and the instantaneous FR [in spikes (sp) per second; bottom traces] obtained at the indicated percentages of $\mathrm{ET}_{\mathrm{CO}_{2}}$.

$1 C)$, even after decerebration, vagotomy, and administration of a neuromuscular blocking agent (González-Forero et al., 2004b). The inspiratory activity of motoneurons was modulated by chemoreceptor-driven changes in response to alterations in $\mathrm{ET}_{\mathrm{CO}_{2}}$. The activity bursts of HMNs increased when $\mathrm{ET}_{\mathrm{CO}_{2}}$ rose and decreased when $\mathrm{ET}_{\mathrm{CO}_{2}}$ declined (Fig. $2 \mathrm{~A}$ ). Relationships obtained between $\mathrm{mFR}$ of burst or $\mathrm{BR}$ and $\mathrm{ET}_{\mathrm{CO}_{2}}$ were linear (Fig. $3 A, B)(\mathrm{r} \geq 0.8 ; p<0.001)$. The slope of the regression line represented the sensitivity $(S)$ or gain of $\mathrm{mFR}$ or $\mathrm{BR}$ to $\mathrm{ET}_{\mathrm{CO}_{2}}$ $\left(S_{\mathrm{mFR}}, S_{\mathrm{BR}}\right.$, respectively) (Fig. $\left.3 A, B\right)$. In control conditions, these rates averaged $8.3 \pm 0.8$ spikes per second per percentage (mean \pm SEM) and $3.8 \pm 0.6$ bursts per minute per percentage, respectively. Thus, the $S_{\mathrm{mFR}}$ was taken as an index of synaptic efficacy on HMNs.

After XIIth nerve crushing, the $S_{\mathrm{mFR}}$ of HMNs declined by $34.6 \pm 6.8 \%$ on day 3 , reached minimum values on day 7 with a decrease of $71.8 \pm 4.5 \%$, and showed initial signs of recovery after the second week (Figs. 2B, 3C), when the first signs of muscle 
A
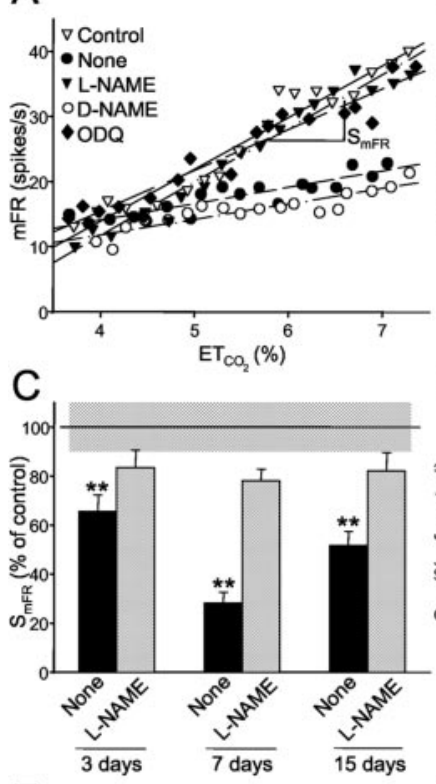

$E$

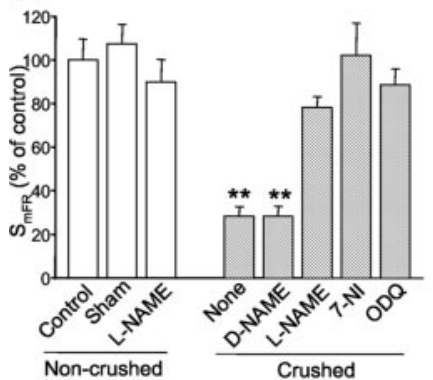

B
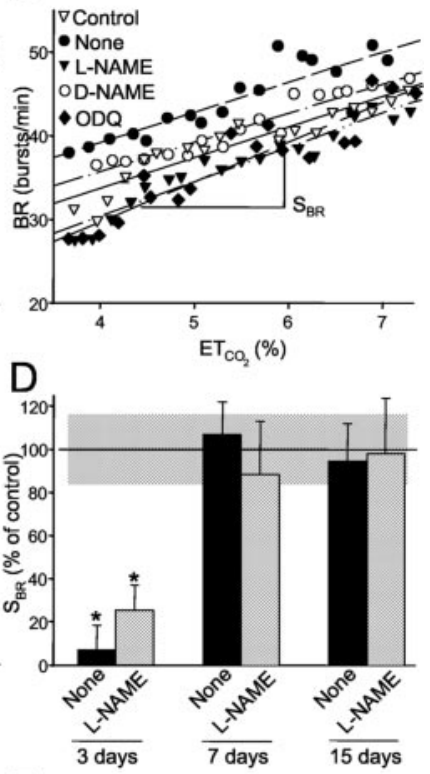

$\mathrm{F}$

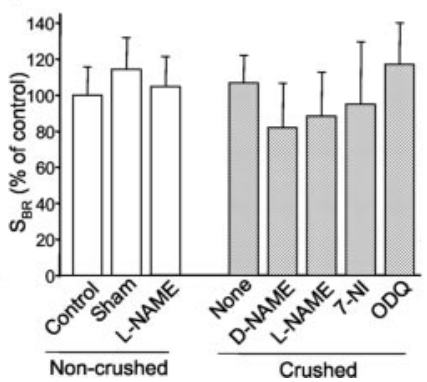

Figure 3. Quantitative effects of NO/CGMP pathway inhibition in central functional alterations. $A, B$, Plots showing the relationships between $\mathrm{mFR}(A)$ per burst or $\mathrm{BR}(B)$ and $\mathrm{ET}_{\mathrm{CO}_{2}}$ for the motoneurons recorded in control $(\nabla)$ stage and in non-treated $(-)$, D-NAME-treated $(\bigcirc)$, L-NAME-treated $(\boldsymbol{\nabla})$, or ODQ-treated $(\checkmark)$ animals $7 \mathrm{~d}$ fter lesion, after grouping and averaging data at $0.2 \%$ intervals of $\mathrm{ET}_{\mathrm{CO}_{2}}$. The slopes of the regression lines represent the neuronal sensitivity to or gain in $\mathrm{ET}_{\mathrm{CO}_{2}}$ changes $\left(S_{\mathrm{mFR}}\right.$, in spikes per second per percentage; $S_{\mathrm{BR}}$, in bursts per minute per percentage). Regression lines are as follows: $\mathrm{mFR}=-18.0+8.0 \times$ $\mathrm{ET}_{\mathrm{CO}_{2}}(r=0.97 ; p<0.001), \mathrm{BR}=19.2+3.6 \times \mathrm{ET}_{\mathrm{CO}_{2}}(r=0.93 ; p<0.001)$ in the control situation; $\mathrm{mFR}=4.0+2.5 \times \mathrm{ET}_{\mathrm{CO}_{2}}(r=0.9 ; p<0.001), \mathrm{BR}=24.8+3.6 \times \mathrm{ET}_{\mathrm{CO}_{2}}(r=0.9$; $p<0.001)$ in the nontreated; $\mathrm{mFR}=2.3+2.4 \times \mathrm{ET}_{\mathrm{CO}_{2}}(r=0.9 ; p<0.001), \mathrm{BR}=21.9+$ $3.5 \times \mathrm{ET}_{\mathrm{CO}_{2}}(r=0.96 ; p<0.001)$ in the D-NAME-treated; $\mathrm{mFR}=-21.3+8.2 \times \mathrm{ET}_{\mathrm{CO}_{2}}(r=$ $0.98 ; p<0.001), \mathrm{BR}=14.0+4.1 \times \mathrm{ET}_{\mathrm{CO}_{2}}(r=0.96 ; p<0.001)$ in the L-NAME-treated; and $\mathrm{mFR}=-9.6+6.3 \times \mathrm{ET}_{\mathrm{CO}_{2}}(r=0.96 ; p<0.001), \mathrm{BR}=10.7+4.7 \times \mathrm{ET}_{\mathrm{CO}_{2}}(r=0.93 ; p<$ $0.001)$ in the ODQ-treated animals. $C, D$, Time course of alterations in $S_{\text {mFR }}(C)$ and $S_{B R}(D)$ after Xllth nerve crushing, measured in nontreated (filled bars) and in chronically L-NAME-treated (gray vertical bars) animals. Slopes are expressed as percentages of the control value at each time point indicated. Horizontal gray bars represent $100 \% \pm$ SEM of control values. $E, F$, Values of $S_{m F R}(E)$ and $S_{B R}(F)$ obtained in noncrushed animals (open bars) in the control stage, in L-NAME-treated animals for $7 \mathrm{~d}$, and at 1 week after sham surgery compared with values obtained at day 7 after crushing (gray bars) in animals receiving the indicated treatments daily. ${ }^{*} p<0.05$, significant differences relative to control animals; one-way ANOVA; post hoc Tukey's test. ${ }^{* *} p<0.05$; significant differences relative to control and NOS inhibitor-treated animals. The numbers of analyzed neurons per condition are as follows: control, $n=41 ; 3 \mathrm{~d}$ nontreated, $n=29 ; 3 \mathrm{~d}$ L-NAME-treated, $n=28 ; 7 \mathrm{~d}$ nontreated, $n=48 ; 7 \mathrm{~d}$ L-NAME-treated, $n=36 ; 15 \mathrm{~d}$ nontreated, $n=52 ; 15 \mathrm{~d}$ L-NAME-treated, $n=31$; sham, $n=16$; noncrushed L-NAME-treated, $n=23 ;$ o-NAME-treated, $n=28 ; 7$-NI-treated, $n=18 ; 0$ DQ-treated, $n=28$.

reinnervation were observed (Fig. $1 K$, Table 1 ). No parallel changes were found in $S_{\mathrm{BR}}$ after lesion (Fig. 3D). The lack of effects on $S_{\mathrm{BR}}$ is crucial for the validation of these results because this parameter is indicative of the integrity of chemosensors and premotor structures. Burst parameters were not affected in the

Table 1. Effect of NOS inhibition on CMAP recovery after XIIth nerve crushing

\begin{tabular}{lllll}
\hline Treatment & Control & $\begin{array}{l}3 \mathrm{~d} \text { after } \\
\text { crushing }\end{array}$ & $\begin{array}{l}7 \mathrm{~d} \text { after } \\
\text { crushing }\end{array}$ & $\begin{array}{l}15 \mathrm{~d} \text { after } \\
\text { crushing }\end{array}$ \\
\hline $\begin{array}{l}\text { None } \\
\begin{array}{l}\text { From crushing day } \\
\quad \text { L-NAME }\end{array}\end{array}$ & $100 \pm 17.5$ & n.e. & n.e. & $29.0 \pm 1.4$ \\
$\quad$ & & & \\
$\quad$ D-NAME & & n.e. & $14.3 \pm 5.1$ & $42.4 \pm 12.9^{*}$ \\
$\begin{array}{l}\text { From day 7 after crushing } \\
\quad \text { L-NAME }\end{array}$ & & n.e. & n.e. & $24.2 \pm 6.3$ \\
$\quad$ D-NAME & & n.e. & n.e. & $16.1 \pm 1.8^{*}$ \\
\hline
\end{tabular}

Values correspond to the CMAP area recorded in untreated control rats and in animals treated daily with L-NAME or D-NAME from the indicated time and are expressed as percentage of the values obtained in noninjured controls. Data values are expressed as mean $\pm \operatorname{SEM}(n=3)$. Asterisks indicate significant differences with respect to the nontreated group ( ${ }^{*} p<0.05$; nonparametric Mann-Whitney $U$ test). n.e., CMAP was not evoked after stimulation of the Xlith nerve at the maximum intensity tested $(<0.1 \mathrm{~mA})$.

sham condition (Fig. $3 E, F$ ). The $S_{\text {BR }}$ declined $3 \mathrm{~d}$ after injury in nontreated and L-NAME-treated animals. Different anesthesia levels could explain $S_{\mathrm{BR}}$ reduction in these two groups. Thus, nerve lesion decreased the chemosensory-mediated responsiveness of HMNs to $\mathrm{ET}_{\mathrm{CO}_{2}}$ changes, with no effects on premotor respiratory modulation. These results are similar to those reported previously (González-Forero et al., 2004b) and are shown here for comparison with the effects of the NO/cGMP pathway inhibitors.

Chronic administration of the NOS inhibitor L-NAME to adult rats, beginning on day of crushing, maintained $S_{\mathrm{mFR}}$ as in the control stage at the three time points tested without affecting $S_{\mathrm{BR}}$ except at day 3 (Figs. $2 C, 3$ ). In contrast, administration of the inactive stereoisomer D-NAME at the same dose did not prevent changes in $S_{\mathrm{mFR}}$ induced by nerve injury on day 7 , when maximum effect was observed in untreated animals (Figs. 2D, 3A,E). This protective effect of L-NAME could be explained by an increased sensitivity of the premotor respiratory network to $\mathrm{ET}_{\mathrm{CO}_{2}}$, but this is unlikely because $S_{\mathrm{mFR}}$ remained unchanged in noninjured animals treated with L-NAME for 1 week (Fig. 3E). Administration of 7-NI, a specific inhibitor of NOS-I, was also protective against the changes in activity induced by nerve lesion (Fig. $3 E$ ). Impairment of synaptic functionality was also prevented by systemic administration of ODQ, a specific inhibitor of sGC (Figs. $2 E, 3 A, E$ ). $S_{\mathrm{BR}}$ was not altered by drugs, which indicates that responsiveness of the respiratory system was preserved in all stages (Fig. $3 B, F$ ). These results indicate that $\mathrm{NO}$ synthesized by NOS-I is a mediator in the molecular processes that convey changes in the motoneuron sensitivity to their afferent drive. Such an effect of NO is exerted through sGC activation and the subsequent increase in cGMP levels in target structures.

\section{The NO/cGMP pathway signals synaptic stripping}

Functional alterations in HMNs were concomitant with synaptic bouton deficits in the HN after nerve lesion (González-Forero et al., 2004b). Accordingly, we performed immunohistochemistry for synaptophysin, a synaptic marker, in sections obtained from animals $7 \mathrm{~d}$ after nerve crushing, and we further investigated the role of $\mathrm{NO}$ on synaptic withdrawal after chronic treatments with inhibitors of the NO/cGMP pathway, using confocal microscopy. We first measured the synaptic density in low-magnification images captured throughout the HN. The histogram of fluorescence intensities and the mean fluorescence intensity of a manually traced area delimiting the $\mathrm{HN}$ were compared in control and experimental nuclei. No significant differences in the measured parameters were observed between the two sides in control animals (Figs. 4C, 5A); however, $7 \mathrm{~d}$ after injury, the histogram of fluorescence intensities was displaced to the left and mean fluo- 


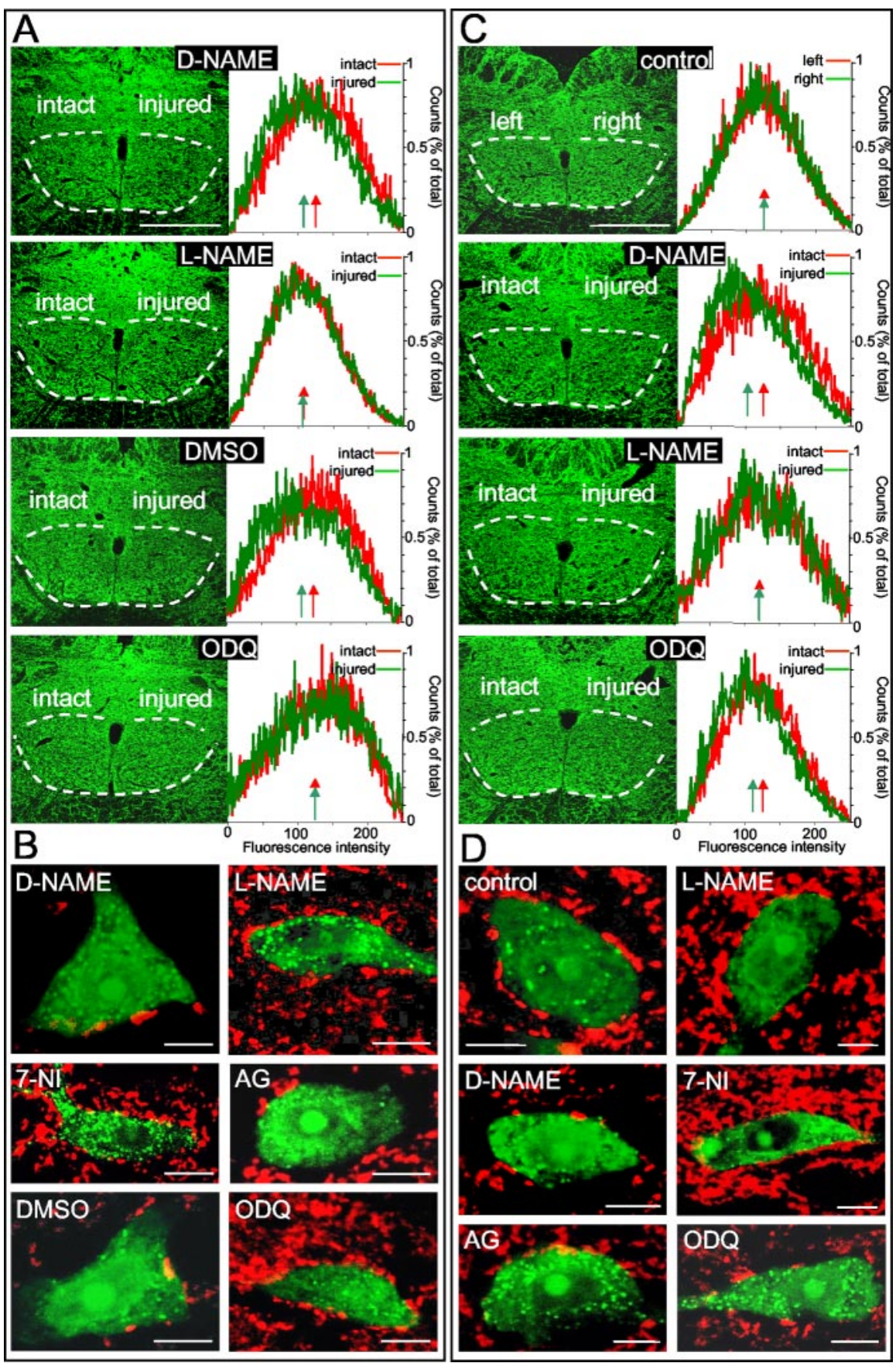

Figure 4. Involvement of the NO/cGMP pathway in central synaptic rearrangement. $A$, Confocal low-magnification photomicrographs (left panels) and their respective histograms of fluorescence intensities (right panels) obtained from coronal sections of animals treated daily with the indicated drugs $7 \mathrm{~d}$ after lesion, immunostained with the synaptic marker synaptophysin. Histograms of fluorescence intensities in the intact (green) and injured (red) sides are represented as the number of counts (expressed as a percentage of the total) with respect to the fluorescence intensities. Arrows mark the mean values of fluorescence intensity for the unoperated (green arrows) and crushed (red arrows) sides. The borders of the HN are indicated by dashed lines. $B$, Confocal high-magnification photomicrographs of HMNs identified by the presence of the tongue-injected retrograde tracer (FluoroGold; green) in sections immunostained for synaptophysin (red) obtained from animals treated daily with the indicated drugs $7 \mathrm{~d}$ after XIIth nerve crushing. C, D, Same as in $A$ and $B$, respectively, except that sections were obtained from animals $15 \mathrm{~d}$ after lesion, in which chemical treatments began on day 7 after Xllth nerve crushing. In the control condition, animals were injected only with the retrograde tracer $7 \mathrm{~d}$ before perfusion. Scale bars: $A, C, 500 \mu \mathrm{m} ; B, D, 10 \mu \mathrm{m}$.

rescence intensity was reduced in the experimental compared with the control side in rats injected with D-NAME, AG, or vehicle used to dissolve ODQ or 7-NI (Figs. 4A, 5A). In L-NAME-, 7-NI-, or ODQ-treated rats, the parameters were similar in both sides (Figs. 4A, 5A). These results were confirmed by inspection of the immunostained material at higher magnification. In the control stage, the number of boutons per $100 \mu \mathrm{m}$ of identified motoneuron perimeter was $14.4 \pm 0.68$ (mean \pm SEM). One week after crushing, in animals treated with D-NAME, AG, or vehicle, the number of boutons was significantly reduced in the experimental side (Figs. $4 B$, $5 B, C)$ by $57.2 \pm 2.9,59.7 \pm 1.4$, and $66.0 \pm$ $1.8 \%$, respectively. These reductions in the synaptic coverage of HMNs $7 \mathrm{~d}$ after axotomy are similar to those described previously using electron microscopy approaches (Sumner, 1975), and they validate our quantification method of synaptic coverage and the effectiveness of the lesion performed here. On the other hand, the number of boutons was maintained near to control value after L-NAME, 7-NI, or ODQ treatment (Figs. $4 B, 5 B, C$ ). No changes in the synaptophysin immunoreactivity of the $\mathrm{HN}$ or in the synaptic coverage on motoneurons from noninjured rats were observed after administration of L-NAME for $7 \mathrm{~d}$ (Fig. $5 A, B$ ), discarding the possibility that systemic NOS inhibition could alter the synaptic structure of HMNs. These observations indicate that neuronal NO is a signal that is needed to induce withdrawal of synaptic terminals on injured motoneurons by a cGMP-dependent mechanism.

\section{NO inhibits central regenerative processes}

NOS-I upregulation is maintained until muscle reinnervation occurs with concomitant recovery of synaptic density in the nucleus (González-Forero et al., 2004b). We further investigated the role of induced $\mathrm{NO}$ synthesis in the $\mathrm{HN}$ on regenerative processes underlying the recovery of complete functionality of the HMNs after axonal injury. For that, chronic treatment with chemicals began $7 \mathrm{~d}$ after XIIth nerve crushing, when alterations in the $S_{\mathrm{mFR}}$ and synaptic coverage of HMNs were maximal. As stated already, signs of $S_{\mathrm{mFR}}$ recovery are observed $15 \mathrm{~d}$ after lesion, but this index still remains significantly reduced with respect to the control stage (Fig. 6A,D). Chronic administration of L-NAME, but not ODQ, raised $S_{\mathrm{mFR}}$ to the values of the control range but did not affect $S_{\text {BR }}$ (Fig. 6). We subsequently analyzed the synaptophysin immunoreactivity using confocal microscopy $15 \mathrm{~d}$ after lesion in animals treated with inhibitors of the NO/cGMP pathway. The histogram of fluorescence intensities and the mean fluorescence intensities were compared between the control and the injured sides. In L-NAME- or 7-NI-treated rats, these parameters were similar to the unoperated side (Figs. 4C, 7A). The effect of L-NAME was stereospecific, because parameters were reduced in the experi- 


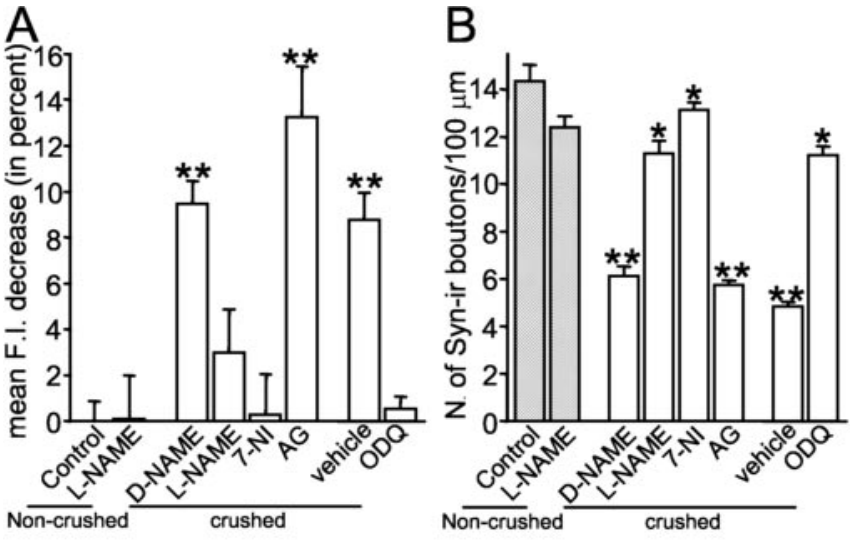

C

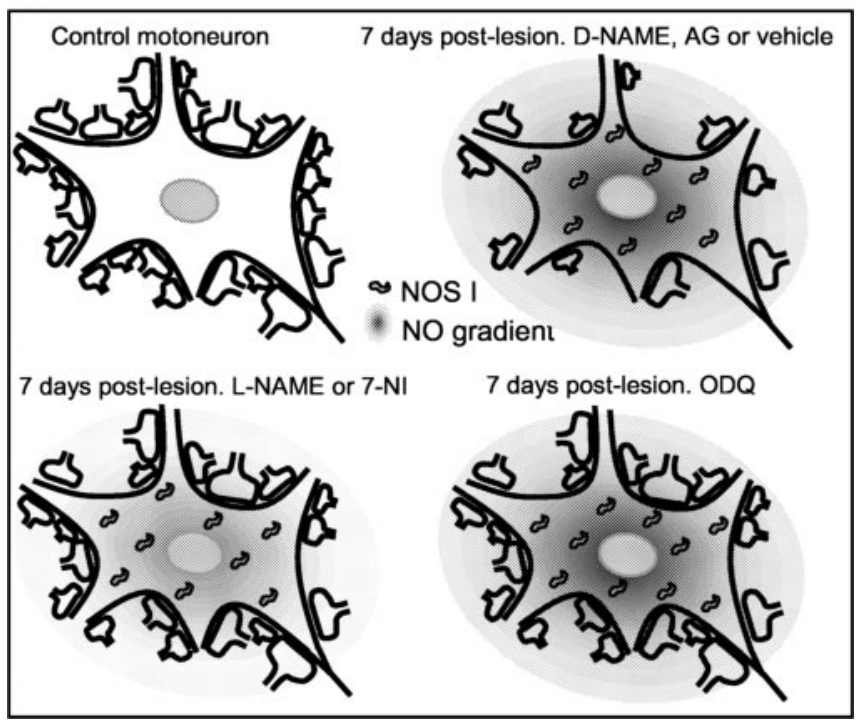

Figure 5. Involvement of the NO/cGMP pathway in synaptic withdrawal. $A$, Decrease in mean fluorescence intensity (F.I.) in the right/injured with respect to the left/unoperated HNs measured in sections immunostained against synaptophysin in controls (gray bars) and $7 \mathrm{~d}$ after XIlth nerve crushing (open bars) from animals treated daily with the indicated chemicals. Data values are means \pm SEM ( $n \geq 16)$. B, The number of synaptophysin-immunoreactive (Syn-ir) boutons per $100 \mu \mathrm{m}$ of HMN perimeter in nonlesioned motoneurons (gray bars) (control value is $14.4 \pm 0.68$ boutons $/ 100 \mu \mathrm{m}$ ) and in motoneurons $7 \mathrm{~d}$ after ipsilateral nerve injury (open bars) from animals treated daily with the indicated drugs. Data values are means $\pm S E M$. The numbers of analyzed motoneurons per condition are as follows: control, $n=75$; noncrushed L-NAME-treated, $n=106$; D-NAME, $n=79$; L-NAME, $n=144$; 7-NI, $n=100 ;$ AG, $n=120$; vehicle, $n=126 ; 0 D Q, n=140$. ${ }^{*} p<0.05$; one-way ANOVA; post hoc Tukey's test, relative to control animals. ${ }^{* *} p<0.05$, relative to control and NOS or $5 G C$ inhibitor-treated animals. $C$, Drawings summarizing the role of the N0/CGMP pathway in changes in the synaptic coverage of HMNs after their axonal injury. Nerve injury induces NOS-I upregulation, which creates a gradient of NO around motoneuron. One week after injury, a dramatic decrease in the synaptic coverage of motoneurons occurs, indicating that axon injury evokes the withdrawal of synaptic boutons on the motoneuron. The synaptic coverage of injured motoneurons is maintained similar to the control condition after treatment with the inhibitors of the NO/cGMP pathway, demonstrating that it is necessary for this pathway to be functional for synaptic detachment, which indicates that neuronal NO plays an anti-synaptotrophic role by a cGMP-dependent mechanism.

mental compared with the control side after administration of D-NAME (Figs. 4C, 7A). The inspection of the immunostained material at higher magnification supported these results. The number of boutons relative to motoneuron perimeter was raised up to control stage values after L-NAME or 7-NI treatments (Figs. $4 D, 7 B, C)$. In contrast, after administration of $A G, D-N A M E$, $\mathrm{ODQ}$, or vehicle, the number of boutons on motoneurons re-

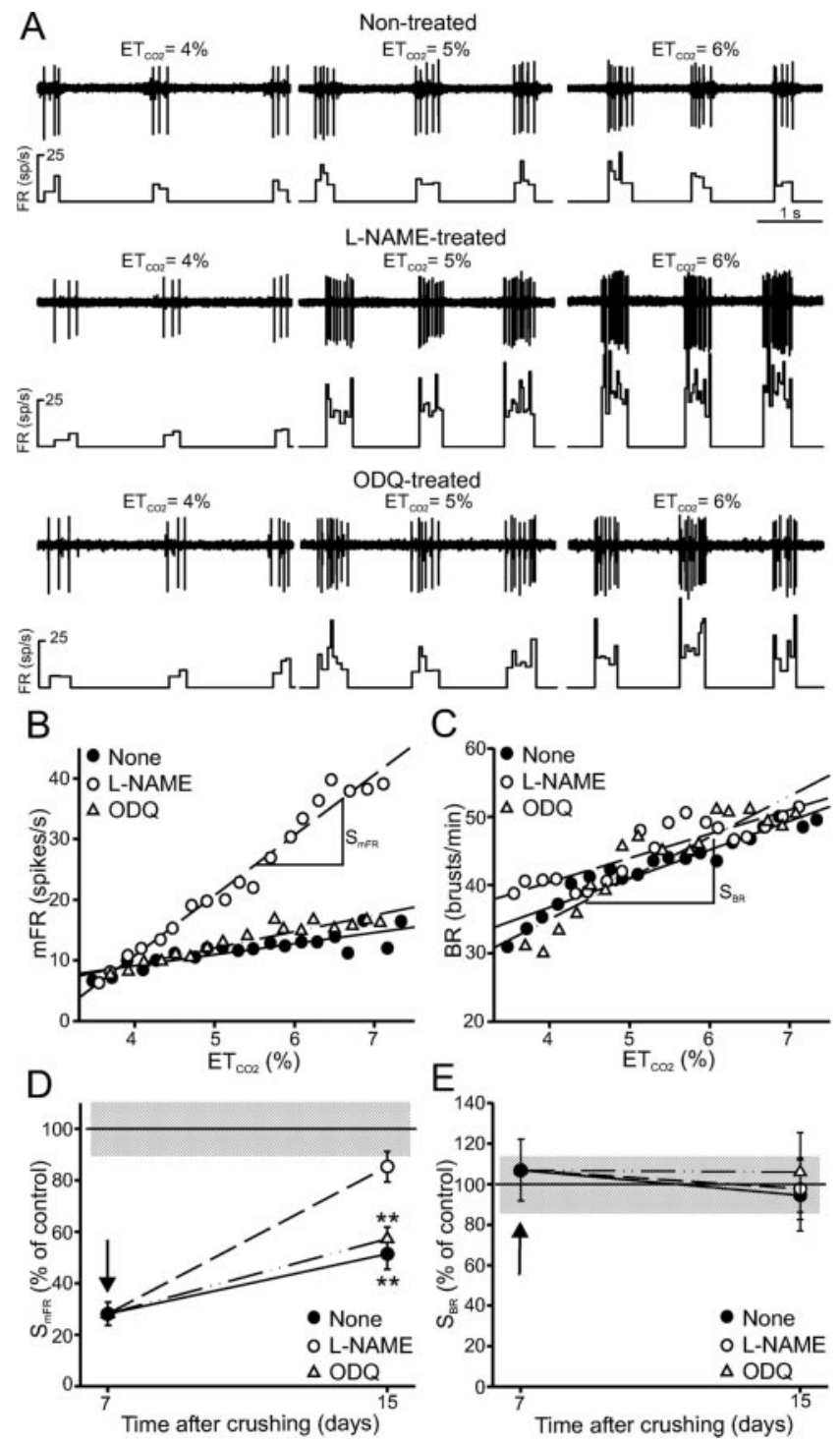

Figure 6. Synthesis of $\mathrm{NO}$ inhibits functional recovery. $A$, Discharge activity modulation at indicated $\mathrm{ET}_{\mathrm{CO}_{2}}$ levels for motoneurons recorded at day 15 after nerve lesion without and after treatment with L-NAME or ODQ beginning on day 7 after injury. Traces represent the extracellular unitary activity (top trace) and the instantaneous FR [in spikes (sp) per second; bottom trace]. $B, C$, Plots showing the relationships between $\mathrm{mFR}(B)$ per burst or $\mathrm{BR}(C)$ and $\mathrm{ET}_{\mathrm{CO}_{2}}$ for the motoneurons illustrated in $A$, after grouping and averaging data at $0.2 \%$ intervals of $\mathrm{ET}_{\mathrm{CO}_{2}}$. The slopes of the regression lines represent the neuronal sensitivity or gain to $\mathrm{ET}_{\mathrm{CO}_{2}}$ changes $\left(S_{\mathrm{mFR}}\right.$, in spikes per second per percentage; $S_{\mathrm{BR}}$, in bursts per minute per percentage). Regression lines are as follows: $\mathrm{mFR}=1.9+1.8 \times \mathrm{ET}_{\mathrm{CO}_{2}}(r=0.9 ; p<0.001), \mathrm{BR}=19.8+4.2 \times$ $\mathrm{ET}_{\mathrm{CO}_{2}}(r=0.95 ; p<0.001)$ in nontreated $(O) ; \mathrm{mFR}=-28.9+9.9 \times \mathrm{ET}_{\mathrm{CO}_{2}}(r=0.99 ; p<$ $0.001), \mathrm{BR}=26.2+3.5 \times \mathrm{ET}_{\mathrm{CO}_{2}}(r=0.9 ; p<0.001)$ in L-NAME-treated $(\mathrm{O})$; and $\mathrm{mFR}=$ $-1.5+2.7 \times \mathrm{ET}_{\mathrm{CO}_{2}}(r=0.94 ; p<0.001), \mathrm{BR}=10.9+6.0 \times \mathrm{ET}_{\mathrm{CO}_{2}}(r=0.91 ; p<0.001)$ in ODQ-treated $(\triangle)$ animals. $D, E$, Values (means \pm SEM) obtained in $S_{\mathrm{mFR}}(D)$ and $S_{\mathrm{BR}}(E)$ at day 7 in the nontreated $(O)$ group and at day 15 in nontreated $(O)$, in L-NAME-treated $(O)$, or in ODQ-treated $(\triangle)$ animals relative to the control (gray horizontal bars; $100 \% \pm$ SEM of control values) group. Arrows indicate the time point of the beginning of treatment. ${ }^{* *} p<$ 0.05; one-way ANOVA; post hoc Tukey's test; statistically significant differences relative to control and L-NAME-treated animals. Numbers of analyzed neurons per condition are as follows: control, $n=41 ; 7 \mathrm{~d}$ nontreated, $n=48 ; 15 \mathrm{~d}$ nontreated, $n=52$; L-NAME-treated, $n=36$; ODQ-treated, $n=28$.

mained significantly reduced in the experimental side (Figs. $4 D$, $7 B, C)$. Together, these results indicate that NO synthesized by NOS-I inhibits synaptogenic phenomena needed to recover normal synaptic coverage and functionality of injured motoneurons by a cGMP-independent mechanism. 

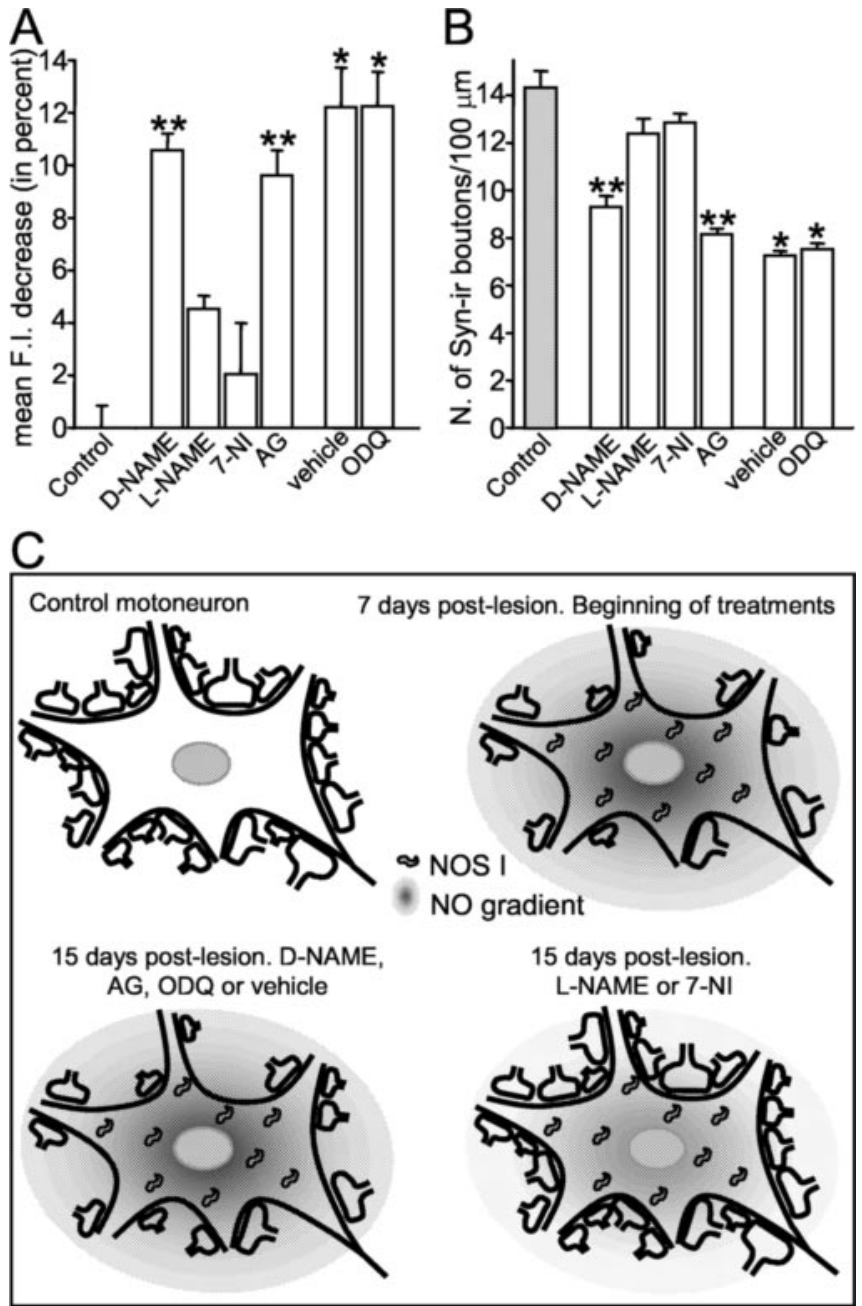

Figure 7. N0 inhibits recovery of synaptic coverage. $A$, Decrease in mean fluorescence intensity (F.I.) in the right/injured with respect to the left/unoperated HNs measured in sections immunostained against synaptophysin in the control stage (gray bar) and $15 \mathrm{~d}$ after Xllth nerve crushing (open bars) from animals treated daily with the indicated chemicals from day 7. Data values are means \pm SEM ( $n \geq 16)$. B, The number of synaptophysin-immunoreactive (Syn-ir) boutons per $100 \mu \mathrm{m}$ of HMN perimeter in the control condition (gray bar) and in motoneurons $15 \mathrm{~d}$ after ipsilateral nerve injury (open bars) from animals treated daily with the indicated drugs from day 7. Data values are means \pm SEM. Numbers of analyzed motoneurons per condition are as follows: control, $n=75 ; \mathrm{D}-\mathrm{NAME}, n=97 ; \mathrm{L}-\mathrm{NAME}, n=89 ; 7-\mathrm{NI}, n=107$; AG, $n=111$; vehicle, $n=233 ; 0 \mathrm{DQ}, n=181 .{ }^{*} p<0.05$; one-way ANOVA; $p$ st hoc Tukey's test; significant differences relative to control animals. ${ }^{* *} p<0.05$, significant differences relative to control and NOS or SGC inhibitor-treated animals. C, Drawings summarizing the role of NO in recovery of the synaptic coverage of HMNs after their axonal injury. Nerve injury induces NOS-I upregulation that creates a gradient of $\mathrm{N} 0$ around the motoneuron. One week after injury, a dramatic decrease in the synaptic coverage of motoneurons occurs that is maintained $15 \mathrm{~d}$ after crushing, indicating that axon injury evokes the withdrawal of synaptic boutons on motoneurons. The synaptic coverage of injured motoneurons is recovered to a control-like condition $15 \mathrm{~d}$ after injury by treatment with L-NAME or 7-NI, but not ODQ or AG, beginning on day 7 after lesion, demonstrating that neuronal $\mathrm{NO}$ acts to inhibit synapse formation, which indicates an anti-synaptogenic role of the NO by a cGMP-independent mechanism.

Then, we tested protein $S$-nitrosylation as a possible mechanism for $\mathrm{NO}$ action in the $\mathrm{HN}$ using an antibody raised against $S$-nitrosylated cysteine (Gow et al., 2002). We measured the immunoreactivity density in low-magnification images captured throughout the HN. In the control stage, no differences between both sides were observed in the mean fluorescence intensity (Fig. $8 A, G)$; however, in sections obtained from animals $15 \mathrm{~d}$ after crushing and treated with D-NAME from $7 \mathrm{~d}$ after lesion, we observed an increase of $73.4 \pm 20.3 \%$ in the injured side compared with the intact side (Fig. $8 B, G$ ). The increase in $S$-nitrosylation was avoided by L-NAME or 7-NI treatment (Fig. $8 C, D, G)$, indicating that NO synthesized by NOS-I induces $S$-nitrosylation of cysteine residues in the HN after XIIth nerve injury. Inspection of the immunostained material at higher magnification demonstrated a punctate-like staining of neuropil in the injured side of D-NAME-treated rats (Fig. $8 E$ ) that was reduced dramatically after L-NAME treatment (Fig. $8 F$ ). These observations suggest that an increased $S$-nitrosylation of proteins could occur in bouton-like structures and represent the mechanism by which NO inhibits synapse formation.

\section{Effects of NOS inhibition on muscle reinnervation}

The preventive or restorative properties of NOS inhibitors could be explained by a faster muscle reinnervation and, consequently, the reestablishment of trophic communication. To study this possibility, the orthodromic field potential (CMAP) recorded in the genioglossus muscle was analyzed in nontreated, L-NAMEtreated, and D-NAME-treated animals at critical time points after nerve crushing. In nontreated rats, CMAP was absent 1 week after XIIth nerve crushing and was still reduced by $71.0 \pm 1.4 \%$ in comparison with the control $15 \mathrm{~d}$ after lesion; however, in daily L-NAME-treated, but not in D-NAME-treated animals, CMAP was already present $7 \mathrm{~d}$ after injury $(85.7 \pm 5.1 \%$ reduction in comparison with the control) and was higher than in the nontreated group $15 \mathrm{~d}$ after nerve lesion (Table 1). These results suggest that inhibition of NOS also promotes muscle reinnervation that could permit a trophic support in motoneurons, which could explain, at least in part, a certain degree of recovery in the $S_{\mathrm{mFR}}$ and synaptic coverage, although only to a limited extent.

On the other hand, in animals treated with L-NAME from day 7 after crushing, CMAPs were even lower on day 15 than those recorded in nontreated animals (Table 1). Such an effect was not observed after treatment with the steroisomer (Table 1). Thus, these results indicate that NO has a positive influence on this phase of muscle reinnervation, discounting the possibility that morphofunctional recovery of motoneurons could be explained by the improvement in the reestablishment of neuromuscular function.

\section{Discussion}

We report here that neuronal NO induced after axonal injury is an anti-synaptotrophic and anti-synaptogenic factor that works through cGMP-dependent and probably $S$-nitrosylationmediated mechanisms, respectively. Reductions in sensitivity to chemoreceptor-modulated inspiratory drive and synaptic coverage of HMNs induced by XIIth nerve crushing were prevented by inhibition of NOS-I or sGC activities; furthermore, a prompt recovery was observed when NOS-I, but not sGC, inhibition began after morphofunctional alterations were maximal. To our knowledge, this is the first report demonstrating a role for NO in synaptic remodeling of the adult mammal CNS; this could underlie phenomena such as learning, memory, and restoration of lost sensorimotor functions that involve synaptic reorganization.

\section{Neuronal NO mediates morphofunctional alterations in the} CNS after nerve injury

Nerve lesions induce functional and structural disturbances in the CNS concomitantly with NOS-I upregulation in the injured motoneurons. We demonstrate here the existence of a causal relationship between the decreased sensitivity of HMN firing to chemoreceptor-modulated inspiratory drives and the appear- 
ance of a new NO source; this relationship can be explained by the NO/cGMPinduced synaptic stripping of motoneurons. The decline in $S_{\mathrm{mFR}}$ and synaptic coverage of HMNs observed after XIIth nerve crushing was prevented by the chronic administration, starting on the day of crushing, of the broad spectrum NOS inhibitor L-NAME. These preventive effects were stereospecific, as demonstrated by administration of the pharmacologically inert stereoisomer D-NAME. Furthermore, the effectiveness of 7-NI, which is a selective inhibitor of NOS-I in vivo (Kelly et al., 1995; Moore and Handy, 1997) and is devoid of the vascular effects of L-NAME (Moreno-López et al., 2004), together with the identification of NOS-I as the iso-enzyme expressed by HMNs after nerve injury and the lack of effects of AG, a selective inhibitor of NOS-II, strongly indicated that the NO source involved in degeneration was indeed of neuronal origin. Prevention of morphofunctional alterations was also observed by administration of ODQ, a specific inhibitor of sGC, which indicates that the NO action was mediated by the increase in cGMP synthesis in the target structures.

The recovery of sensitivity and synaptic coverage took place in parallel with NOS-I downregulation, suggesting a limiting action of induced NO on central restorative events. Supporting this hypothesis, improvement of central disturbances was accelerated when NOS-I inhibition began on day 7 after injury; however, recovery was not hastened by treatment with D-NAME, AG, or ODQ. Consequently, neuronal NO obstructs regenerative events by a cGMPindependent mechanism. Enhancement of $S$-nitrosylated cysteine immunoreactivity after nerve injury and reduction by NOS-I inhibition point to protein $S$-nitrosylation as the mechanism by which NO could prevent the recovery of synaptic coverage. In support of this, previous findings have demonstrated that NO collapses neuronal growth cones by a modification of cyteine residues on substrate proteins (Hess et al., 1993).

It could be argued that the weak muscle reinnervation observed $7 \mathrm{~d}$ after treatment with L-NAME in the crushed group might be sufficient to give trophic support to HMNs, which then recover synaptic integrity; however, synaptic function and coverage were still reduced $15 \mathrm{~d}$ after crushing in the nontreated group, when functional muscle reinnervation was stronger. These findings run counter to the view that actions of the NO/cGMP pathway inhibitors on central processes were fully explained by the reestablishment of myocyte-derived trophic support.

Induced neuronal NO is necessary for synaptic stripping, but is it sufficient?

The evidence indicates that $\mathrm{NO}$ is necessary to induce withdrawal of synaptic boutons on insulted motoneurons and inhibits the formation of new synapses necessary to recover normal functionality up to the reestablishment of neuromuscular function. The
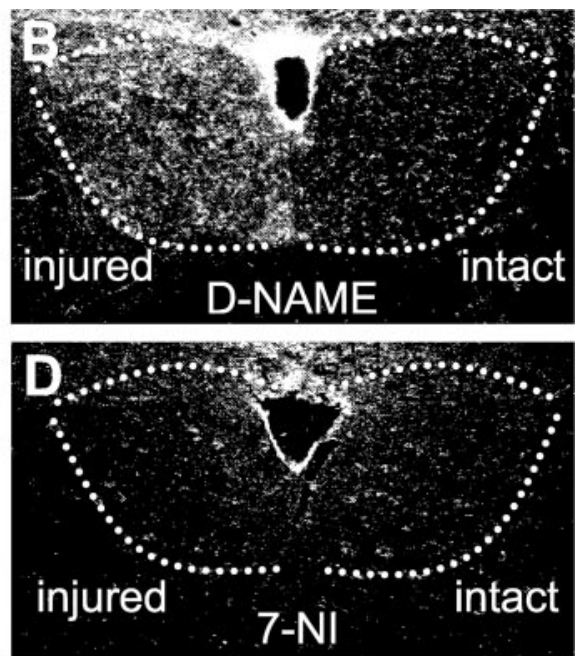

intact
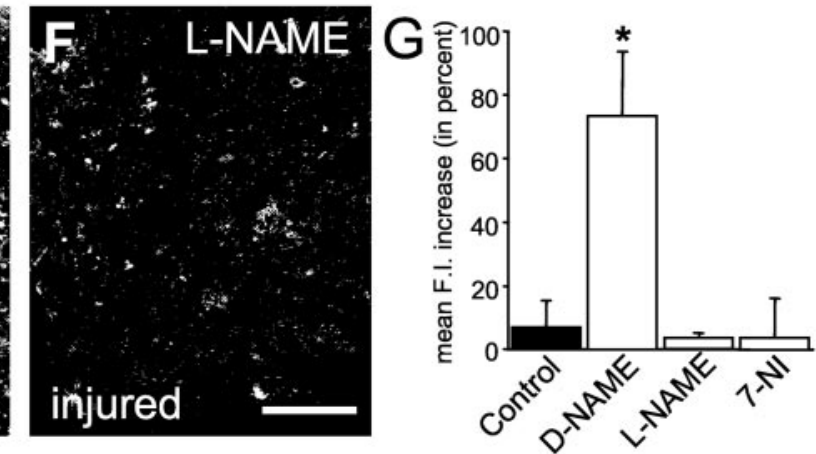

Figure 8. S-nitrosylation as a potential cGMP-independent mechanism underlying prevention of synaptic reestablishment.

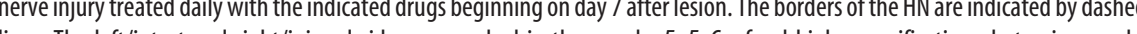
treated daily with the indicated chemicals from day 7. Data values are means \pm SEM $(n \geq 10)$. ${ }^{*} p<0.05$; nonparametric Mann-Whitney $U$ test; significant differences relative to measurements obtained at control stage.

synthesis of NO, although necessary, may not be sufficient to induce withdrawal of boutons, because widely distributed specific neurons constitutively express NOS-I (Bredt et al., 1990), without apparent instability of synapses reaching them or their neighboring neurons. Additional molecules involved in the cascade of events induced by interruption of trophic support, or by alteration in the neurotrophic factor level itself, participate jointly with NO in the control of bouton dynamics. On this aspect, Ernst et al. (2000) demonstrated that growth cone collapse and axon retraction caused by $\mathrm{NO}$ can be blocked by pretreatment with brain-derived neurotrophic factor (BDNF). Furthermore, increasing BDNF levels enhanced axon arborization and synapse formation during development (Alsina et al., 2001) and inhibited NOS-I expression in axotomized motoneurons (Wu et al., 2003). These findings suggest that the anti-synaptotrophic and anti-synaptogenic functions of NO are manifested in an environment with abnormal levels of neurotrophic factors, as occurs after axonal injury.

\section{Involvement of NO in synaptogenic events in the CNS}

In recent years, many different molecules have been reported to be involved in synaptogenic events (Benson et al., 2001; Garner et 
al., 2002; Yamagata et al., 2003). NO is a candidate diffusible molecule linking spatiotemporally events that occur in presynaptic and postsynaptic structures to form a new synaptic contact. It has been found that NO contributes to the elimination of retinotectal projections during development (Wu et al., 1994; Ernst et al., 1999). In the opposite direction, NO mediates functional synaptic plasticity phenomena (Holscher, 1997) as well as synaptogenesis in developing and regenerating olfactory receptor neurons (Roskams et al., 1994) and triggers the growth of presynaptic filopodia that rapidly lead to the formation of new synaptic contacts in hippocampal organotypic slice cultures (Nikonenko et al., 2003).

These apparently contradictory roles could be the consequence of the different molecular environments encountered in developing and adult brains, as well as different experimental conditions, and could be caused by the compromising of trophic support after nerve injury. Furthermore, it is well known that NO production is coupled with neuron activity by glutamate activation of NMDA receptors (Garthwaite et al., 1988). Induced transient opening of NMDA receptors will discretely evoke production of NO in silent preparations or in neurons with low activity, as in organotypic cultures (Nikonenko et al., 2003). Under these conditions, discrete and transient NO synthesis could favor synaptogenesis and functional synaptic plasticity; however, HMNs are characterized by an uninterrupted inspiratory activity mediated by activation of glutamatergic receptors (Wang et al., 2002) that subsequently activates NOS-I. Moreover, XIIth nerve axotomy increases the expression of these receptors in the HN (García del Caño et al., 2000). In these circumstances, induced NO synthesis is prolonged and could have negative effects on synaptic maintenance and/or synaptic formation.

\section{Neuronal induced NO synthesis in neurological disorders}

Overproduction of NO from NOS-I may occur after persistent stimulation of NMDA receptors mediating glutamate excitotoxicity. This is a common feature leading to neuronal death in traumatic brain injury, cerebral ischemia, amyotrophic lateral sclerosis, and Parkinson's and Alzheimer's diseases. As we discussed in the previous paragraph, this could be the case in our experimental lesion model in which NMDA receptors partially mediate the continuous inspiratory activity, evoking a persistent source of NO.

In response to a central traumatic lesion, two sources of NO are induced: (1) at the site of the lesion, where a glial scar is established (Rao et al., 1999; Petrov et al., 2000), and (2) NOS upregulation in the axotomized neuron (Herdegen et al., 1993; Chen and Aston-Jones, 1994; Saxon and Beitz, 1994). The two NO-synthesizing structures have different roles in the survival capacity of the injured neuron. At the lesion site, in a very poor environment for axonal regeneration, growth cones collapse by the inhibitory effect of synthesized NO (Hess et al., 1993) and synaptogenic processes are impaired, with the consequent inadequate trophic support from target to the injured neuron. Thus, in insults such as ischemia, excitotoxicity, and axotomy (Kashii et al., 1996; Iadecola et al., 1997; Klöcker et al., 1998), the activation of NOS has negative consequences for neuronal survival.

In amyotrophic lateral sclerosis, characterized by loss of motor neurons and extensive astrogliosis in the motor cortex and spinal cord, NOS-I upregulation occurs in motoneurons and reactive astrocytes (Anneser et al., 2001; Catania et al., 2001; Sasaki et al., 2001). It is also suggested that neuronally derived NO is involved in the etiology of Parkinson's and Alzheimer's diseases, in which there is upregulation of NOS-I in neurons and/or glial cells (Przedborski et al., 1996; Eve et al., 1998; Lüth et al., 2000; Šimic' et al., 2000; Fernández-Vizarra et al., 2004). In support of this, it has been reported that inhibition of NOS-I prevents MPTP-induced parkinsonism (Hantraye et al., 1996). Thus, we believe that targeted inhibition of NOS-I could attenuate or delay the pathogenicity of these neurodegenerative disorders. This idea is supported by the application of exogenous synaptotrophic factors, such as cerebrolysin (Mallory et al., 1999), in the treatment of patients with mild Alzheimer's disease (Ruther et al., 1994).

\section{Concluding remarks}

We propose a mechanism of action of NO in the course of diverse physiopathological events that involve NOS-I upregulation and alterations in physiological neurotrophic levels. Endogenously induced NO creates a new and unfavorable microenvironment, at least for synaptic boutons, around the insulted neuron, and $\mathrm{NO}$ acts via cGMP to promote synaptic withdrawal. Continuous NO synthesis inhibits axonal growth, probably by $S$-nitrosylation of proteins, and prevents the formation of new synapses. This situation is maintained, at least in the case of motoneurons, until axon regeneration leads to the reestablishment of trophic communication and synthesis of NO is downregulated, with the subsequent recovery of motoneuron functionality. In the absence of reinnervation, sustained NO synthesis and neuronal deafferentation could trigger a cascade of events that concludes with the apoptosis of the injured neuron.

\section{References}

Alsina B, Vu T, Cohen-Cory S (2001) Visualizing synapse formation in arborizing optic axons in vivo: dynamics and modulation by BDNF. Nat Neurosci 4:1093-1101.

Anneser JMH, Cookson MR, Ince PG, Shaw PJ, Borasio GD (2001) Glial cells of the spinal cord and subcortical white matter up-regulate neuronal nitric oxide synthase in sporadic amyotrophic lateral sclerosis. Exp Neurol 171:418-821.

Benson DL, Colman DR, Huntley GW (2001) Molecules, maps and synapse specificity. Nat Rev 2:899-909.

Bredt DS, Hawing PH, Snyder SH (1990) Localization of nitric oxide synthase indicating a neural role for nitric oxide. Nature 347:768-770.

Catania MV, Aronica E, Yankaya B, Troost D (2001) Increased expression of neuronal nitric oxide synthase spliced variants in reactive astrocytes of amyotrophic lateral sclerosis human spinal cord. J Neurosci 21:1-5.

Chen S, Aston-Jones G (1994) Cerebellar injury induces NADPHdiaphorase in Purkinje and olivary neurons in the rat. Exp Neurol 126:270-276

Ernst AF, Wu HH, El-Fakahany EE, McLoon SC (1999) NMDA receptormediated refinement of a transient retinotectal projection during development requires nitric oxide. J Neurosci 19:229-235.

Ernst AF, Gallo G, Letourneau PC, McLoon SC (2000) Stabilization of growing retinal axons by the combined signaling of nitric oxide and brain-derived neurotrophic factor. J Neurosci 20:1458-1469.

Eve DJ, Nisbet AP, Kingsbury AE, Hewson AL, Daniel SE, Lees AJ, Marsden CD, Foster OJF (1998) Basal ganglia neuronal nitric oxide synthase mRNA expression in Parkinson's disease. Mol Brain Res 63:62-71.

Fernández-Vizarra P, Fernández AP, Castro-Blanco S, Encinas JM, Serrano J, Bentura ML, Muñoz P, Martínez-Murillo R, Rodrigo J (2004) Expression of nitric oxide system in clinically evaluated cases of Alzheimer's disease. Neurobiol Dis 15:287-305.

García del Caño G, Gerrikagoitia I, Sarasa M, Matute C, Martínez-Millán L (2000) Ionotropic glutamate receptor subunits are differentially regulated in the motoneuronal pools of the rat hypoglossal nucleus in response to axotomy. J Neurocytol 29:509-523.

Garner CC, Zhai RG, Gundelfinger ED, Ziv NE (2002) Molecular mechanisms of CNS synaptogenesis. Trends Neurosci 25:243-250.

Garthwaite J, Charles SL, Chess-Williams R (1988) Endothelium-derived relaxing factor release on activation of NMDA receptors suggests role as intercellular messenger in the brain. Nature 336:385-388.

González-Forero D, Benítez-Temiño B, de la Cruz RR, Pastor AM (2004a) 
Functional recovery in the peripheral and central nervous system after injury. In: Brain damage and repair. From molecular research to clinical therapy (Herdegen T, Delgado-García JM, eds), pp 285-305. Durdrecht, The Netherlands: Kluwer.

González-Forero D, Portillo F, Sunico CR, Moreno-López B (2004b) Nerve injury reduces basal activity and chemosensory-mediated modulation of hypoglossal motoneurones in the adult rat. J Physiol (Lond) 557.3:991-1011.

Gow AJ, Chen Q, Hess DT, Day BJ, Ischiropoulos H, Stamler JS (2002) Basal and stimulated protein S-nitrosylation in multiple cell types and tissues. J Biol Chem 277:9637-9640.

Hantraye P, Brouillet E, Ferrante R, Palfi S, Dolan R, Matthews RT, Beal MF (1996) Inhibition of neuronal nitric oxide synthase prevents MPTPinduced parkinsonism in baboons. Nat Med 2:1017-1021.

Herdegen T, Brecht S, Mayer B, Leah J, Kummer W, Bravo R, Zimmermann N (1993) Long-lasting expression of JUN and KROX transcription factors and nitric oxide synthase in intrinsic neurons of the rat brain following axotomy. J Neurosci 13:4130-4145.

Hess DT, Patterson SI, Smith DS, Skene JHP (1993) Neuronal growth cone collapse and inhibition of protein fatty acylation by nitric oxide. Nature 366:562-565.

Holscher C (1997) Nitric oxide, the enigmatic neuronal messenger: its role in synaptic plasticity. Trends Neurosci 20:298-303.

Hwang JC, Bartlett Jr D, St. John WM (1983) Characterization of respiratory-modulated activities of hypoglossal motoneurons. J Appl Physiol 55:793-798.

Iadecola C, Zhang F, Casey R, Nagayama M, Ross ME (1997) Delayed reduction of ischemic brain injury and neurological deficits in mice lacking the inducible nitric oxide synthase gene. J Neurosci 17:9157-9164.

Kashii S, Mandai M, Kikuchi M, Honda Y, Tamura Y, Kaneda K, Akaike A (1996) Dual actions of nitric oxide in $N$-methyl-D-aspartate receptormediated neurotoxicity in cultured retinal neurons. Brain Res 711:93-101.

Kelly PA, Ritchie IM, Arbuthnott GW (1995) Inhibition of neuronal nitric oxide synthase by 7-nitroindazole: effects upon local cerebral blood flow and glucose use in the rat. J Cereb Blood Flow Metab 15:766-773.

Klöcker N, Cellerino A, Bähr M (1998) Free radical scavenging and inhibition of nitric oxide synthase potentiates the neurotrophic effects of brainderived neurotrophic factor on axotomized retinal ganglion cells in vivo. J Neurosci 18:1038-1046.

Lüth HJ, Holzer M, Gertz H-J, Arendt Th (2000) Aberrant expression of nNOS in pyramidal neurons in Alzheimer's disease is highly co-localized with $221^{\text {ras }}$ and $16^{\text {INK4a }}$. Brain Res 852:45-55.

Mallory M, Honer W, Hsu L, Johnson R, Rockenstein E, Masliah E (1999) In vitro synaptotrophic effects of cerebrolysin in NT2N cells. Acta Neuropathol (Berl) 97:437-446.

Mendell LM (1984) Modifiability of spinal synapses. Physiol Rev 64:260-324.

Moore PK, Handy RLC (1997) Selective inhibitors of neuronal nitric oxide synthase. Is no NOS really good NOS for the nervous system? Trends Pharmacol Sci 18:204-211.

Moreno-López B, Romero-Grimaldi C, Noval JA, Murillo-Carretero M, Matarredona ER, Estrada C (2004) Nitric oxide is a physiological inhibitor of neurogenesis in the adult mouse subventricular zone and olfactory bulb. J Neurosci 24:85-95.
Nikonenko I, Jourdain P, Muller D (2003) Presynaptic remodeling contributes to activity-dependent synaptogenesis. J Neurosci 23:8498-8505.

Petrov T, Page AB, Owen CR, Rafols JA (2000) Expression of the inducible nitric oxide synthase in distinct cellular types after traumatic brain injury: an in situ hybridization and immunocytochemical study. Acta Neuropathol (Berl) 100:196-204.

Prast H, Philippu A (2001) Nitric oxide as modulator of neuronal function. Prog Neurobiol 64:51-68.

Przedborski S, Jackson-Lewis V, Yokoyama R, Shibata T, Dawson VL, Dawson TM (1996) Role of neuronal nitric oxide in 1-methyl-4-phenyl1,2,3,6-tetrahydropyridine (MPTP)-induced dopaminergic neurotoxicity. Proc Natl Acad Sci USA 93:4565-4571.

Rao VL, Dogan A, Bowen KK, Dempsey RJ (1999) Traumatic injury to rat brain upregulates neuronal nitric oxide synthase expression and L- $\left[{ }^{3} \mathrm{H}\right]$ nitroarginine binding. J Neurotrauma 16:865-877.

Rodrigo J, Springall DR, Uttenthal O, Bentura ML, Abadia-Molina F, Riveros-Moreno V, Martinez-Murillo R, Polak JM, Moncada S (1994) Localization of nitric oxide synthase in the adult rat brain. Philos Trans $\mathrm{R}$ Soc Lond B Biol Sci 345:175-221.

Roskams AJ, Bredt DS, Dawson TM, Ronnet GV (1994) Nitric oxide mediates the formation of synaptic connections in developing and regenerating olfactory receptor neurons. Neuron 13:289-299.

Ruther E, Ritter R, Apecechea M, Freytag S, Windish M (1994) Efficacy of the peptidergic nootropic drug cerebrolysin in patients with senile dementia of the Alzheimer's type (SDAT). Pharmacopsychiatry 27:32-40.

Sasaki S, Shibata N, Iwata M (2001) Neuronal nitric oxide synthase immunoreactivity in the spinal cord in amyotrophic lateral sclerosis. Acta Neuropathol (Berl) 101:351-357.

Saxon DW, Beitz AJ (1994) Cerebellar injury induces NOS in Purkinje cells and cerebellar afferent neurons. NeuroReport 5:809-812.

Šimic' G, Lucassen PJ, Krsnik Ž, Krušlin B, Kostovic' I, Winblad B, Bogdanovic' N (2000) nNOS expression in reactive astrocytes correlates with increased cell death related DNA damage in the hippocampus and entorhinal cortex in Alzheimer's disease. Exp Neurol 165:12-26.

Sumner BEH (1975) A quantitative analysis of boutons with different types of synapse in normal and injured hypoglossal nuclei. Exp Neurol 49:406-417.

Titmus MJ, Faber DS (1990) Axotomy-induced alterations in the electrophysiological characteristics of neurons. Prog Neurobiol 35:1-51.

Wang J, Irnaten M, Venkatesan P, Evans C, Baxi S, Mendelowitz D (2002) Synaptic activation of hypoglossal respiratory motoneurons during inspiration in rats. Neurosci Lett 332:195-199.

Wu HH, Williams CV, McLonn SC (1994) Involvement of nitric oxide in the elimination of a transient retinotectal projection in development. Science 265:1593-1596.

Wu W, Li L, Yick LW, Chai H, Yang Y, Prevette DM, Oppenheim RW (2003) GDNF and BDNF alter the expression of neuronal NOS, c-Jun, and p75 and prevent motoneurons death following spinal root avulsion in adult rats. J Neurotrauma 20:603-612.

Yamagata M, Sanes JR, Weiner JA (2003) Synaptic adhesion molecules. Curr Opin Cell Biol 15:621-632.

Yu WHA (1997) Regulation of nitric oxide synthase expression in motoneurons following nerve injury. Dev Neurosci 19:247-254. 